\title{
MEGALOBLASTIC ANAEMIA IN PREMATURE INFANTS
}

\author{
BY \\ O. P. GRAY and E. BLANCHE BUTLER \\ From the Departments of Child Health and Obstetrics, Welsh National School of Medicine
}

(RECEIVED FOR PUBLICATION FEBRUARY 18, 1964)

The common anaemia in premature infants is iron deficiency anaemia, but megaloblastic anaemia can also occur and here we report three such cases. Our interest in megaloblastic anaemia was stimulated by a recent case in which megaloblastic anaemia developed when a low phenylalanine diet was being given for treatment of phenylketonuria (Royston and Parry, 1962). In the discussion of this paper Royston and Parry advocated the need for more frequent marrow biopsy in the unexplained anaemias of infancy. As a result of this policy we have discovered the following cases in premature infants.

\section{Case Reports}

Case 1. A male infant weighing $850 \mathrm{~g}$. was born on November 12,1962, the third child in the family. The mother was aged 39 years and her pregnancy had ended prematurely at 29 weeks. During the pregnancy the mother herself had suffered from a severe iron deficiency anaemia. This was not diagnosed until November 6, 1962 when she presented with a haemoglobin level of $6.6 \mathrm{~g} . / 100 \mathrm{ml}$. Her diet had been adequate but she had received no supplementary iron during pregnancy. She was admitted on November 8, 1962 for a course of parenteral iron but she was already draining liquor and went into labour spontaneously three days later. By this time she had received $850 \mathrm{mg}$. of parenteral iron and $1,100 \mathrm{ml}$. blood were transfused when labour began. The foetal heart was not heard for an hour before birth and the chance of survival seemed slight, but a live child in a fairly good condition was born. As the mother's membranes had been ruptured for four days the infant was given oral erythromycin stearate $40 \mathrm{mg}$./day for the first week. During the first 36 hours he showed mild respiratory distress, and the maximum Silverman score (Silverman and Andersen, 1956) was 4 . He became mildly jaundiced but the serum bilirubin did not rise above $14 \mathrm{mg} . / 100 \mathrm{ml}$. On the fifth day he was noted to have developed some lower sternal retraction, and two days later crepitations were heard on the right side of the chest. He improved and progress was normal until the 14th day. Then his colour became a little dusky at times, the insuction increased, the respiratory rate rose to 60 a minute, and there were fine crepitations again on the right side. He was given intramuscular streptomycin sulphate and a further course of oral erythromycin stearate as he was thought to have a bronchopneumonia; but response to this treatment was poor and he was therefore given cloxacillin, and $\gamma$-globulin $250 \mathrm{mg}$. At this time coliform organisms were isolated from the umbilicus and from gastric washings. On the 24 th day the haemoglobin level was $12 \cdot 1 \mathrm{~g} . / 100 \mathrm{ml}$., but in the following week there was a rapid fall and at the age of $\mathbf{3 0}$ days the haemoglobin was $7 \cdot 7$ g., RBC 2,030,000/c.mm., haematocrit $24 \%$, MCV 116 c. $\mu, \mathrm{MCH} 37.5 \mu \mu \mathrm{g}$., MCHC $32 \%$. The white cell count was $8,000 /$ c.mm. with 2 nucleated red cells per 100 white cells. The red cells in the blood film showed anisocytosis and poikilocytosis, and many macrocytes were present. Red cell precursors were seen in the blood film and in the buffy coat; these were mainly normoblastic in type but many were atypical with eccentric nuclei or double nuclei, and a few contained Howell Jolly bodies. A few cells showed nuclei transitional in type between the normoblast and megaloblast pattern. White cell changes were not prominent in this case.

The bone marrow was examined on the 33rd day, and erythropoiesis was found to be mainly megaloblastic in type. Occasional giant metamyelocytes were seen. Blood taken later the following day showed a serum folate level of $3.0 \mu \mu \mathrm{g} . / \mathrm{ml}$. and a serum vitamin B12 level of $134 \mu \mu \mathrm{g} . / \mathrm{ml}$. On the 33rd day the child was, therefore, given folic acid $10 \mathrm{mg}$. intramuscularly, and treatment was continued with folic acid $10 \mathrm{mg}$./day orally for the next three weeks. The maximum reticulocyte count was $32 \%$ and this was reached on the sixth day of treatment (the 39th day of life). This coincided with a marked improvement in the child's condition; a systolic murmur, previously heard, had gone, the insuction was no longer present, and the respiratory rate had dropped to 33 a minute. The haemoglobin rose initially and reached a level of $10.2 \mathrm{~g} . / 100 \mathrm{ml}$. on the $51 \mathrm{st}$ day, but there was a further slight fall, and by the 64th day the haemoglobin was stationary at $8.9 \mathrm{~g}$. The reticulocyte count was $9 \cdot 2 \%$. A blood film examined at this time showed evidence of iron deficiency and this was treated with parenteral iron $25 \mathrm{mg}$. on alternate days to a total of 75 mg. The vitamin B12 level was again estimated and found to be $132 \mu \mu \mathrm{g} . / \mathrm{ml}$. This was still below the lower limit of normal as given by Boger, Bayne, Wright, and Beck (1957) and therefore vitamin B12 $300 \mu \mathrm{g}$. intramuscularly was given over a period of one week. Fig. 1 shows the haemoglobin and reticulocyte response to folic acid. 


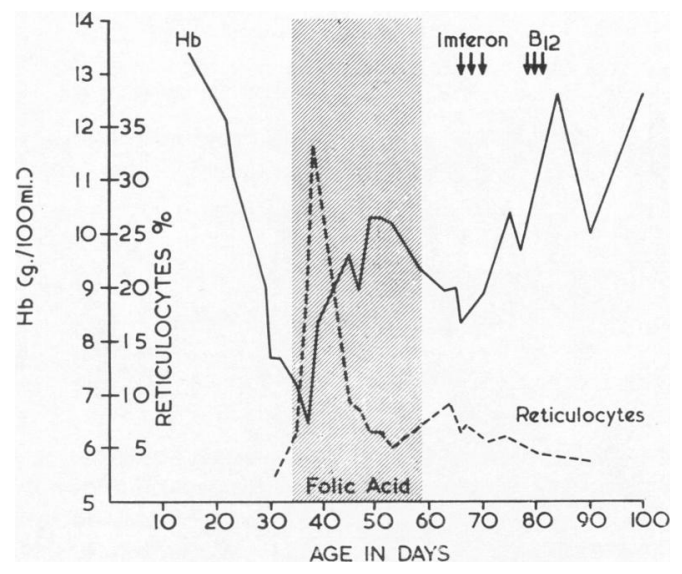

FIG. 1.-Case 1. The marked reticulocyte and haemoglobin response to folic acid, followed by a later haemoglobin rise after Imferon.

Case 2. (This was the second case briefly mentioned by Parry, 1963). A male infant weighing 1,000 g. was born on December 1, 1961. The mother was 34 years and she had a severe pre-eclamptic toxaemia which necessitated delivery by caesarean section at the 33rd week. The infant's condition was good at birth and he progressed well until the 14th day. He then developed insuction, the respiratory rate rose to 60 a minute and at times his colour was dusky. He was treated as a chest infection with 'albamycin-T,' but the insuction became worse, though at this time there were no added sounds in the lungs. By the 40th day coarse râles were heard in the chest and coliform organisms were isolated from the nose and stomach washings. The temperature rose to $38^{\circ} \mathrm{C}$., and a systolic murmur was heard. On the 48th day the haemoglobin level was found to have fallen to $6.5 \mathrm{~g}$./ $100 \mathrm{ml}$. (44\%), RBC 2,000,000/c.mm., haematocrit $22 \%$, MCV 110 с. $\mu$, MCH $77 \mu \mu \mathrm{g}$., MCHC 29\%, WBC 8,700/ c.mm., platelets $500,000 /$ c.mm. A number of nucleated red cells were seen in the blood film and, though the majority of these were normoblastic in type, some contained Howell Jolly bodies and a few showed a nuclear structure very similar to that seen in megaloblasts. In addition occasional multisegmented polymorphs were seen. The bone marrow was examined on the 50th day and this confirmed the presence of megaloblastic erythropoiesis, and many giant metamyelocytes were found. Blood taken at this time showed a serum vitamin B12 level of $334 \mu \mu \mathrm{g} . / \mathrm{ml}$. (facilities were not then available for serum folate estimations). Treatment with folic acid 20 mg./day was begun on the 54th day and continued for three weeks. The maximum reticulocyte count was $21.5 \%$ and was reached on the 7 th day after starting treatment (the 61st day of life), but insuction was less by the fourth day and had disappeared entirely after two weeks. Further progress in this case was uneventful. The marrow examination was repeated 9 days after beginning folic acid and in this specimen normoblastic erythropoiesis was seen, though occasional giant meta-

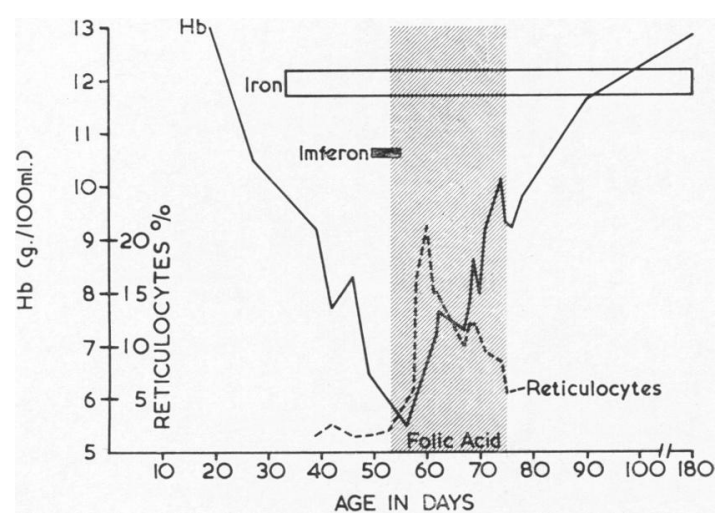

FIG. 2.-Case 2. $\mathrm{Hb}$ and reticulocyte response to folic acid.

myelocytes were still present. Fig. 2 shows the haemoglobin and reticulocyte response to folic acid.

Case 3. A boy weighing 1,150 g. was born on July 29, 1963. The mother had an antepartum haemorrhage at the 32nd week of her pregnancy and following this went into premature labour. The child's condition at birth was poor, the Apgar (1953) score being only 4, but he was resuscitated and had normal spontaneous respiratory movements at 5 minutes. He then developed the respiratory distress syndrome and within an hour of birth needed treatment with intravenous sodium bicarbonate for associated acidosis. He was also anaemic with a haemoglobin of $8.9 \mathrm{~g} . / 100 \mathrm{ml}$. There was no obvious cause for the anaemia, the mother's blood group was $\mathbf{O}$ $\mathrm{Rh}+\mathrm{ve}$, and no antibodies were found during pregnancy; the infant's blood group was $\mathrm{O} R \mathrm{R}+\mathrm{ve}$. It was thought that there had been a haemorrhage from the foetal side of the placenta at the time of the antepartum haemorrhage. The mother's liquor was draining for six days before delivery and so the child was given intramuscular streptomycin sulphate and oral erythromycin stearate for 5 days. He made a slow but satisfactory recovery from the respiratory distress syndrome, but for a fortnight he was hypotonic and lying in the frog position. During this time the haemoglobin level rose to $11.3 \mathrm{~g}$., presumably a response to the anaemia at birth. It then began to fall again, and by the 19 th day was $8 \cdot 1 \mathrm{~g}$. Insuction was also present and a few crepitations appeared over the left upper chest, and so the child was again given oral erythromycin stearate. He became more lethargic and on the 24th day he had the first of several severe apnoeic attacks which lasted for about 5 minutes. The blood picture on the 21st day was as follows: $\mathrm{Hb} 7 \cdot 7 \mathrm{~g} . /$ $100 \mathrm{ml}$., RBC 1,970,000/c.mm., haematocrit $21 \%$, MCV 107 c. $\mu$, MCH $39 \mu \mu$ g., MCHC 36\%, reticulocytes $1.6 \%$. Megaloblasts, transitional cells, and atypical normoblasts were seen in the blood film and in the buffy coat. Macrocytes and macro-ovalocytes were present but, as in 
Case 1, white cell changes were minimal. Marrow biopsy was taken on the 25 th day, and though this was a poor specimen, it was possible to confirm the presence of megaloblasts. Blood was taken for vitamin B12 and serum folate levels, but because of a technical error only the serum B12 level was estimated; this was $182 \mu \mu \mathrm{g} . / \mathrm{ml}$.

Treatment was started with folic acid on the 24th day, $4 \mathrm{mg}$./day. The maximum reticulocyte count was only $7.4 \%$ in this case, but the extent of the reticulocytosis was obscured as a blood transfusion was given. This became necessary because the apnoeic attacks were coincident with the increasing anaemia and threatened the child's life. It is our belief that cerebral hypoxia is one of the factors in apnoeic attacks in infants, and so the anaemia was thought to be largely responsible for these attacks. We felt unable to wait for the natural response to folic acid to relieve the situation, and so gave a small blood transfusion of $20 \mathrm{ml}$. on the 26th day; a further $35 \mathrm{ml}$. of blood was given on the 33rd day because of a further drop in haemoglobin level to $6.9 \mathrm{~g}$. Further progress was uneventful with no more cyanotic attacks, and at the age of 36 days the haemoglobin was $13 \cdot 6 \mathrm{~g}$. Fig. 3 shows the haemoglobin and reticulocyte response to folic acid.

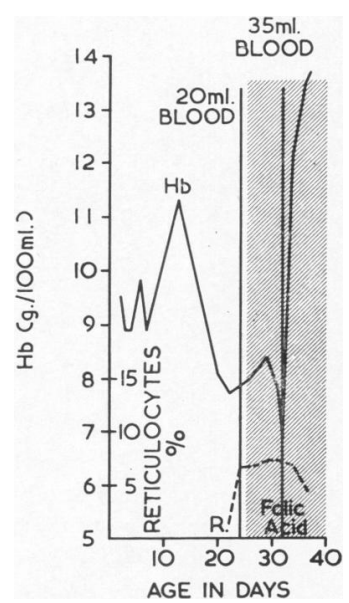

Fig. 3.-Case 3. The marked reticulocyte and haemoglobin rise follows folic acid and blood transfusions, the latter given because of the infant's deterioration.

\section{Discussion}

These three premature infants had megaloblastic anaemia which responded well to folic acid. The anaemia was diagnosed at a very early age, the youngest child was 25 days and the oldest 50 days. The age incidence of megaloblastic anaemia in infancy is generally given as between 8 and 14 months, but Zuelzer and Rutzky (1953) found that cases of less than 4 months were not uncommon, while their own youngest case was 6 weeks old.

These cases had several features in common. Their birth weights were low, 850, 1,000, and $1,150 \mathrm{~g}$.
Before the development of the megaloblastic anaemia they each had an illness thought to be a chest infection. The respiratory rate was raised, they were listless and lethargic, hypotonic, and developed insuction. Radiographs showed an increase in bronchovascular markings. Each child was treated with antibiotics. In each case the megaloblastic anaemia was accompanied by an increase in insuction, and after the experience with the first child the diagnosis was suggested in the other two by this sign, together with progressive anaemia. It seems possible that an infant born prematurely has a low reserve of folic acid and that infection exhausts the small supplies available. It is also possible that the antibiotics used might interfere with folic acid metabolism to produce a relative deficiency.

According to the figures given by Boger et al. (1957) for normal infants at birth, the serum vitamin B12 level was well within the normal range in Case 2, at the lower level of the normal range in Case 3, and below that level in Case 1. In a series of paired sera from mothers and babies at one hospital Boger et al. found that the range in babies was 190-1,400 $\mu \mu \mathrm{g}$./ $\mathrm{ml}$., with an average of $560 \mu \mu \mathrm{g} . / \mathrm{ml}$. It is possible that here we should take into account variations in results from different laboratories. In the series of Boger the average serum B12 level in women at term was $310 \mu \mu \mathrm{g} . / \mathrm{ml}$. with a range of $200-490$. In the laboratory at this hospital the average serum B12 level in a group of women in the last four weeks of pregnancy was $218 \mu \mu \mathrm{g}$. $/ \mathrm{ml}$. with a range of 85-520. This suggests that slightly lower levels are normally obtained in this laboratory, and that even Case 1 had a serum B12 level which can be considered to be within the normal range. In addition to this, Luhby, Cooperman, MacIver, and Montgomery (1960) state that, 'serum cyanocobalamin levels below $120 \mu \mu \mathrm{g} . / \mathrm{ml}$. in infants reflect cyanocobalamin deficiency'. Work is in progress at this hospital on serum vitamin B12 and serum folate levels in normal and premature infants paired with maternal levels at the time of delivery, but this is not sufficiently advanced to give a normal range for this laboratory.

In general the value is shown of careful examination of the blood film and buffy coat in premature infants who have a progressive anaemia that does not respond to iron. In one case (S.T.) megaloblasts were seen in the peripheral blood, and in the other two cases the appearances were highly suggestive of a megaloblastic anaemia. It is now our practice to examine the buffy coat of every premature infant with a haemoglobin below 9 g.l $100 \mathrm{ml}$., and when it is not conclusive to proceed to marrow biopsy. It is interesting to note that in 
these three infants white cell changes were only prominent in one (Case 2). It is suggested that in the treatment of established megaloblastic anaemia in premature infants the initial treatment should be folic acid $20 \mathrm{mg}$./day, given intramuscularly, but as a prophylactic, our present practice is to give folic acid $5 \mathrm{mg}$./day in addition to the routine vitamins $\mathrm{A}, \mathrm{D}$, and $\mathrm{C}$ and oral iron commencing at the end of the first week.

\section{Summary}

Three premature babies developed megaloblastic anaemia in the early days of life. They responded well to folic acid. It is thought that the chest infection that each had before the anaemia exhausted the small folic acid reserves and was partly responsible for the anaemia.

We are grateful to Professors A. G. Watkins and A. S. Duncan for their help and advice in the preparation of this article; to Dr. T. E. Parry for advice and help with the bone marrow examinations; to Dr. J. L. Withey for estimating the Vitamin B12 and folate levels; to Mr. R. Marshall of the Department of Medical Illustration, Cardiff Royal Infirmary, and to Mr. P. Stinchcombe for the figures; and to Miss K. E. Heide and Miss A. S. Caldwell for their kind secretarial help.

\section{REFERENCES}

Apgar, V. (1953). A proposal for a new method of evaluation of the newborn infant. Curr. Res. Anaesth., 32, 260.

Boger, W. P., Bayne, G. M., Wright, L. D., and Beck, G. D. (1957) Differential serum vitamin B12 concentrations in mothers and infants. New Engl. J. Med., 256, 1085.

Luhby, A. L., Cooperman, J. M., MacIver, J. E., and Montgomery, R. D. (1960). Folic acid and cyanocobalamin (Vitamin B12) metabolism in kwashiorkor. Amer. J. Dis. Child., 100, 542.

Parry, T. E. (1963). Nutritional megaloblastic anaemia in infancy. In Paediatric Pathology Club. Proceedings of the Eighth Annual Meeting. Arch. Dis. Childh., 38, 95.

Royston, N. J. W., and Parry, T. E. (1962). Megaloblastic anaemia complicating dietary treatment of phenylketonuria in infancy. ibid., 37, 430 .

Silverman, W. A., and Andersen, D. H. (1956). A controlled clinical trial of effects of water mist on obstructive respiratory signs, death rate and necropsy findings among premature infants. Pediatrics, 17, 1.

Zuelzer, W. W., and Rutzky, J. (1953). Megaloblastic anemia in infancy. Advanc. Pediat., 6, 243. 